\title{
Wildflower seed sales as incentive for adopting flower strips for native bee conservation: a cost-benefit analysis
}

\section{Authors: Casey M. Delphia, Kevin M. O'Neill, and Laura A. Burkle}

This is a pre-copyedited, author-produced version of an article accepted for publication in Journal of Econominc Entomology following peer review. The version of record, cited below, is available online at: https://doi.org/10.1093/jee/toz191.

Delphia, Casey M, Kevin M O’Neill, and Laura A Burkle. "Wildflower Seed Sales as Incentive for Adopting Flower Strips for Native Bee Conservation: A Cost-Benefit Analysis." Journal of Economic Entomology (July 18, 2019). doi:10.1093/jee/toz191. 
Casey M. Delphia

Montana State University

Bozeman, MT 59717

Phone: 413-281-8314

E-mail: casey.delphia@montana.edu

Wildflower seed sales as incentive for adopting flower strips for native bee conservation: a cost-benefit analysis.

Author list:

Casey M. Delphia ${ }^{1,2}$, Kevin M. O’Neill², and Laura A. Burkle ${ }^{1}$

\begin{abstract}
Affiliation line:
1 Department of Ecology, Montana State University, Bozeman, MT 59717-3460, USA

2 Department of Land Resources and Environmental Sciences, Montana State University, Bozeman, MT 59717-3120, USA
\end{abstract}




\begin{abstract}
Improving pollinator habitat on farmlands is needed to further wild bee conservation and to sustain crop pollination in light of relationships between global declines in pollinators and reductions in floral resources. One management strategy gaining much attention is the use of wildflower strips planted alongside crops to provide supplemental floral resources for pollinators. However, farmer adoption of pollinator-friendly strategies has been minimal, likely due to uncertainty about costs and benefits of providing non-crop flowering plants for bees. Over three years, on four diversified farms in Montana USA, we estimated the potential economic profit of harvesting and selling wildflower seeds collected from flower strips implemented for wild bee conservation, as an incentive for farmers to adopt this management practice. We compared the potential profitability of selling small retail seed packets versus bulk wholesale seed. Our economic analyses indicated that potential revenue from retail seed sales exceeded the costs associated with establishing and maintaining wildflower strips after the second growing season. A wholesale approach, in contrast, resulted in considerable net economic losses. We provide proof-of-concept that, under retail scenarios, the sale of native wildflower seeds may provide an alternative economic benefit that, to our knowledge, remains unexplored. The retail seed-sales approach could encourage greater farmer adoption of wildflower strips as a pollinator conservation strategy in agroecosystems. The approach could also fill a need for regionallyproduced, native wildflower seed for habitat restoration and landscaping aimed at conserving native plants and pollinators.
\end{abstract}

\title{
Keywords
}

Economic benefits, Habitat management, Native plants, Pollinator conservation, Wild bees. 


\section{Introduction}

Animal-mediated pollination is an ecosystem service of great economic, ecological, and societal value (e.g., Losey and Vaughn 2006). Pollination services are particularly important in agriculture; an estimated $15-30 \%$ of U.S. food production and 35\% of global production depends on animals for pollination (Allen-Wardell et al. 1998, Losey and Vaughn 2006, Klein et al. 2007).

Bees are important pollinators for crop and non-crop plant species (Michener 2007), and managed honey bees (Apis mellifera L.) (Hymenoptera: Apidae) are the predominant crop pollinators globally (Klein et al. 2007). However, declines in honey bee health (e.g., Ellis et al. 2010) and increased awareness of the risks of relying too heavily on one species for crop pollination highlight the importance of wild bees (e.g., Winfree et al. 2007, Geldmann and Gonzalez-Varo 2018). For example, wild bees are more efficient pollinators than honey bees for many crops (e.g., blueberries, Javorek et al. 2002; raspberries and blackberries, Cane 2005; tomatoes, Greenleaf and Kremen 2006; and squash, Hurd et al. 1971), and which contribute significantly to crop pollination worldwide (Losey and Vaughn 2006, Klein et al. 2007, Gallai et al. 2009, Garibaldi et al. 2013).

The development of farm-management strategies that encourage wild bee populations is an important priority for sustainable agriculture (e.g., Goulson et al. 2015), especially given the scarcity of non-crop flowering plants in highly-managed croplands (Biesmeijer et al. 2006, Potts et al. 2010, Winfree et al. 2011). Farmers are often unable to modify the habitats surrounding their fields. However, they can enact small-scale, bee-friendly habitat changes on their own lands. One promising strategy is the use of native wildflower plantings (i.e., "flower strips") designed to supply continuous floral resources for bees beyond the blooming period of crops 
(Tuell et al. 2008, Isaacs et al. 2009, Blaauw and Isaacs, 2014, Williams et al. 2015, Lundin et al. 2018).

Farmers may be reluctant to adopt wildflower strips without better information on their benefits and costs (Wratten et al. 2012, Blaauw and Isaacs 2014, Uyttenbroeck et al. 2016), despite government incentives and cost-sharing programs directed at implementing farm-based wildflower plantings (e.g., Vaughan and Skinner 2008, Haaland, Naisbit and Bersier 2011, Batáry et al. 2015). Research documenting the value of flower plantings to support pollinators primarily comes from Europe rather than North America (reviewed in Venturini et al. 2017a). Globally, however, only a few studies have examined the economics of floral resource provisioning for pollinators, including profits from increased crop yield and costs of implementing these practices (e.g., Blaauw and Isaacs 2014, Pywell et al. 2015, Morandin et al. 2016, Venturini et al. 2017b). Additional research demonstrating economic benefits of wildflower plantings will likely aid growers to decide whether to adopt this technique (Vanslembrouck et al. 2002, Pascual and Perrings 2007, Uyttenbroeck et al. 2016). For example, a recent economic experiment examining landowner enrollment decisions demonstrated that without monetary incentives that outweigh the crop production value of that land, adoption of pollinator habitat strategies are minimal (Jones Ritten et al. 2017). In addition, those lands that are planted with pollinator habitat are lower quality lands (i.e., marginal lands with low production value), which may provide low-quality pollinator habitat.

Not all pollinator-dependent crops experience increased pollination from pollinator habitat management practices (Sardinas and Kremen 2015). Different bee communities respond to the presence of wildflower plantings in different ways, ultimately affecting crop visitation rates and pollination (Burkle et al. 2017). Furthermore, diversified farms, which are comparatively 
lessstudied in regards to flower plantings compared to intensive agroecosystems, may already provide abundant and diverse floral resources, with maximal crop pollination even without wildflower strips (Kennedy et al. 2013, Scheper et al. 2013, 2015). The lack of consistent cropyield benefits due to presence of wildflower strips might reduce farmer interest in pollinator conservation. However, we are presently far from a practical understanding of the environmental and economic benefits of wildflower strips within the numerous agroecosystems across North America and globally.

Over the last 30 years, the demand for native plant products has grown along with increasing awareness of the importance of native plants in a variety of applications, including revegetation projects, wildlife habitat restoration, conservation plantings, landscaping, and public and private gardens (Richards et al.1998, Aldrich 2002, Potts et al. 2002, Norcini 2006, Erickson 2008, Tuell et al. 2008, Isaacs et al. 2009, Peppin et al. 2010, Bujak 2015, Lundin et al. 2018). For example, with respect to pollinators, the United States Department of Agriculture currently offers a variety of incentive-based programs to establish habitat using native plants such as the Pollinator Habitat Initiative (CP-42) under the Conservation Reserve Program (CRP) and the Environmental Quality Incentive Program (EQIP) (Vaughan and Skinner 2008). More recently, the U.S. government promoted a strategy focused on using native plants to "restore or enhance 7 million acres of land for pollinators over the next 5 years" (The White House 2015a). Current revegetation policies already stress the use of native plants, but can easily be dismissed in certain circumstances such as limited seed availability (Richards et al. 1998, Erickson 2008, USDA FS 2012). To avoid this problem, strategies are needed to increase local native-plant seed supplies and establish seed reserves to ensure a stable and affordable native seed supply (White House 
2015a, b). Partnering with farmers growing native plants as forage for pollinators might be one relatively efficient way to increase seed availability.

To further explore the potential benefits of establishing on-farm pollinator habitats, we planted native perennial-wildflower strips on four diversified farms in the Northern Rockies of Montana USA. Over three years, we assessed whether wildflower strips could profit farmers via native plant-seed sales beyond their associated costs. We examined retail and wholesale seedsales approaches. This was motivated by local (Bujak 2015) and national (e.g., Whitehouse 2015a, b) demand for native wildflower seeds. We are not aware of other studies evaluating wildflower strips implemented for bee conservation as marketable wildflower seed sources.

\section{Materials and Methods}

\section{Study sites and flower strips}

This research was conducted in southwest Montana USA from 2013-2015 at four small, diversified vegetable farms (i.e., market gardens) each having approximately 3-10 acres in cultivation annually (Supp. Table S1). Each farm grew numerous, locally-marketed crops, including squash and pumpkins (Cucurbita pepo L.), tomatoes (Solanum lycopersicum L.), and cucumbers (Cucumis sativus L.). Two farms were certified organic and the others followed organic or sustainable practices. Honey bee colonies $(\leq 5)$ were occasionally kept on-farm, but all farms were located within a 5-mile radius of at least one commercial apiary (https://mtplants.mt.gov/Hypersensitive/BeeHyperSearch.aspx). The farms, which were up to 30 $\mathrm{km}$ apart, varied in micro-climatic conditions, weed densities, and management practices, including irrigation methods and planting bed preparation (Supp. Table S1). 
We selected nine native perennial wildflower species for the flower strips: Campanula rotundifolia L., Erigeron speciosus (Lindl.) DC., Gaillardia aristata Pursh, Geranium viscosissimum Fisch. and C.A. Mey. Ex C.A. Mey., Helianthus maximiliani Schrad., Heterotheca villosa (Pursh) Shinners, Monarda fistulosa L., Penstemon confertus Douglas ex Lindl., and Phacelia hastata Douglas ex Lehm.. To provide pollen and nectar for a diversity of bee species across each growing season, we chose species with different floral colors, morphologies, and bloom phenologies (Tuell et al. 2008). Furthermore, we selected wildflower species that thrive in full sun and are drought tolerant. These abiotic factors reflect typical agricultural field conditions in this region.

In spring 2013, we started plants in the greenhouse in cone-tainers (SC10U-98 cells per tray) from seed. In early June on each farm, we transplanted a total of 153 plugs into c. 1 x 33 m strips prepared in a manner consistent with each farm's planting bed preparation methods (Supp. Table S1). We used plugs rather than direct seeding to hasten flower-strip establishment and enhance similarity among the farms. Each wildflower strip was planted with three, c. $1 \mathrm{~m}^{2}$ replicates of each of the nine species for a total of 27 plots per strip and was positioned at one edge of each farm, so as not to not interfere with farming activities.

\section{Calculating costs and estimated profits associated with wildflower strips}

We recorded all labor (i.e., number of hours and people) and monetary costs associated with 1) establishing and maintaining flower strips (e.g., plant materials, planting the strips, weeding) and 2) taking a seed-sales approach (e.g., hand-harvesting, cleaning, and packaging seed) from 2013-2015 for each farm. We considered two different suppliers for purchasing plant materials for flower strips, including a local wholesale nursery and an online retail nursery 
specializing in native plants. We also considered retail and wholesale selling approaches for estimating the value of wildflower seeds. We calculated potential income from seed sales using our seed yields for each year, farm, and wildflower species and 1) current retail values for seed packets (USD/packet/unit weight) obtained by researching local and online seed vendors and 2) current wholesale values for bulk seed obtained from a local wholesale seed company. To determine overall potential net profit, we compared all costs incurred during 2013-2015 against the projected income from retail and wholesale wildflower seed sales in 2014 and 2015 for 1) each farm (i.e., the entire flower strip) and 2) each wildflower species individually, because each species had unique attributes that contributed to the overall costs. Blaauw and Isaacs (2014) used a labor rate of $\$ 10 / \mathrm{h}$ in their analyses, but we increased that to $\$ 12 / \mathrm{h}$ (USD) based on guidance from a local nursery.

\section{Costs of establishing and maintaining flower strips (2013-2015)}

Plant material costs. We estimated the cost to purchase plant materials using prices from two commercial sources that specialize in native plants, a local Montana wholesale nursery that

charges $\$ 1.30$ per plug (Scenario 1; 2016 pricing) and an online retail nursery that charges $\$ 3.66$ per plug (Scenario 2; 2016 pricing).

Planting costs. Because we used perennials, planting costs were incurred only in 2013. For each farm in 2013, we recorded the total time (h) to plant each wildflower strip, the number of plugs planted of each species, and the total number of plugs of all species (Supp. Tables S2 and S3). We calculated the proportion of plugs of each species planted $\left(\mathrm{P}_{\mathrm{F}}\right)$, which was the same at each farm (Supp. Table S2). We calculated the costs to plant each species per farm as: Planting Cost $=\left(\right.$ total hours to plant strip $\left.\times \mathrm{P}_{\mathrm{F}}\right) \times($ labor rate per hour $)($ Supp. Tables S2-S4). 
Watering costs. At each farm, the wildflower strips were on the same grower-installed irrigation system as adjacent crops. Therefore, the wildflower strips received irrigation when the crops did regardless of whether they needed it. We did not factor this cost into our analysis because this did not require any additional farmer labor or water costs. However, in 2013, the flower strips required supplemental irrigation beyond the weekly crop watering to increase establishment success, so we factored this cost into our analysis because it was additional labor outside of normal farm operations. For each farm in 2013, we recorded the total time to handwater each wildflower strip (Supp. Table S3) and calculated watering costs for each species as: Watering Cost $=\left(\right.$ total hours to water strip $\left.\times \mathrm{P}_{\mathrm{F}}\right) \times($ labor rate per hour $)($ Supp. Tables S2-S4).

Weeding costs. For each farm in 2013-2015, we recorded the total time to weed each wildflower strip (Supp. Table S3). In 2013 (year 1), all species required the same basic weeding effort because of similar areas of bare soil around each plant regardless of species. Thus, we calculated weeding cost for each species as: Weeding Cost $=$ (total hours to weed strip / number of flower species) x (labor rate per hour) (Supp. Tables S2-S4). However, for 2014 and 2015, weeding times varied among wildflower species based on the area of ground covered by our plants, many of which had spread, covering much of the bare space between plants and suppressing weed germination and growth. We realized this difference in effort between plant species was important to consider in our analyses. Therefore, to distribute the overall weeding effort for the entire strip among the different plant species, we created a simple index of relative weeding effort for each wildflower species based on plant characteristics (i.e., spread, density, size) that affected weeding effort. Species that were less time consuming to weed received a score of 1 , whereas those that were approximately twice as time consuming received a score of 2 , 
for a total of 12 units of effort across all nine species (Supp. Table S2). The proportion of weeding effort for each species $\left(\mathrm{P}_{\mathrm{w}}\right)$ thus equals the weeding index of each species divided by 12 (Supp. Table S2). We calculated weeding costs for each species in 2014 and 2015 as: Weeding Cost $=\left(\right.$ total hours to weed strip $\left.\times \mathrm{P}_{\mathrm{W}}\right) \times($ labor rate per hour) (Supp. Tables S2-S4). To ensure that our indices were not leading to inaccuracies or biases, we also conducted a simple robustness analysis in which we redid our overall cost-benefit calculations under the assumption of equality of weeding effort among species.

Opportunity costs. For each farm in 2013-2015, we included the opportunity cost, or the cost incurred from displacing other salable crops in order provide ground to plant wildflower strips, for each of the four farms. We used the 43,560 Initiative (i.e., gross revenue goal of $\$ 43,560$ per acre, or $\$ 1$ per $\mathrm{ft}^{2}$; net revenue goal of approximately half gross revenue, or $\$ 0.50$ per $\mathrm{ft}^{2}$ ) as a guide to calculate gross and net revenue lost (Odeh and Hairston 2014). This model applies to small, diversified farms with retail and direct-to-consumer sales. It likely overestimates the actual value lost per foot through crop displacement on each farm (Pers. Comm., M. Burgess, Assistant Professor, Montana State University, Bozeman, MT). For example, mean gross revenue (2017) for 10 crops at one participating farm in our study was $\$ 0.65$ per $\mathrm{ft}^{2}$ (Pers. Comm., M. Burgess). Therefore, we calculated the net opportunity costs for the space each flower species occupied each year as: Opportunity Cost $=($ area of flower strip in $\mathrm{ft}^{2} \mathrm{x}$ net revenue per $\left.\mathrm{ft}^{2}\right) /($ number of flower species) (Supp. Table S4). This cost was the same among flower species and farms because each flower strip was the same size on each farm and each flower species was provided the same amount of space to grow within the strip. 


\section{Costs of harvesting, cleaning, testing, and packaging seed (2014-2015)}

Seed harvesting cost. For each farm in 2014, we recorded the total time to harvest seed from each wildflower strip (Supp. Table S3). Species varied in the level of difficulty to collect seeds due to plant traits, such as plant architecture, seed type and dispersal mechanism, and the synchrony of seed maturation rates. For example, seeds of some species matured almost all at once, while in other species seeds matured over several weeks and required multiple seed collecting trips. Therefore, we created a simple index of relative harvesting effort for each flower species based on these plant characteristics. Species for which it was relatively less time consuming to harvest seed received a score of 1 , whereas species for which it was most time consuming to harvest seed received a score of 3 , and those falling in between received a score of 2, for a total of 16 units of effort among all nine wildflower species (Suppl. Table S2). The proportion of harvesting effort for each flower species $\left(\mathrm{P}_{\mathrm{H}}\right)$ thus equals the harvesting index of each species divided by 16 (Supp. Table S2). We calculated seed harvesting costs for each species in 2014 as: Seed Harvesting Cost $=\left(\right.$ total hours to harvest seed in strip $\left.\times \mathrm{P}_{\mathrm{H}}\right) \mathrm{x}$ (labor rate per hour) (Supp. Tables S2-S4). As with weeding effort (see Weeding costs), we also conducted a simple robustness analysis in which we redid our overall cost-benefit calculations under the assumption of equality of seed harvesting effort among species to ensure that our indices were not leading to inaccuracies or biases. Because plants were generally similar in size during the years we collected seed, we assumed that seed harvesting cost was the same in 2015 as in 2014 (Supp. Table S4).

Seed cleaning costs. We cleaned seeds by hand and used a series of wire-mesh sieves as well as a seed blower (E.L. Erickson Products- Model B, Brookings, South Dakota) when it was 
appropriate for the type of seed. For plant species with large awns, such as E. speciosus, $G$. aristata, and $H$. villosa, we removed all non-seed plant debris by hand. In 2014, we recorded the total time to clean seed of each wildflower species cumulatively across all farms, so we could not calculate individual seed cleaning times for each farm (Supp. Table S5). However, in 2015, we recorded the total time to clean seed of each species for each farm. This provided us with data on the proportion of time spent cleaning seeds of each species on each farm in 2015, hereafter referred to as $\mathrm{P}_{\mathrm{C}(\text { Farms 1-4) }}$ (Supp. Table S2). Therefore, for 2014 analyses, we assumed a similar proportion of time cleaning seeds as in 2015 and calculated an estimated seed cleaning cost for each species at each farm as: Seed Cleaning Cost $=$ (total hours to clean seed of each species $\mathrm{x}$ $\left.\mathrm{P}_{\mathrm{C}(\mathrm{Farm})}\right) \mathrm{x}$ (labor rate per hour) (Supp. Tables S2 and S4). For 2015, seed cleaning costs for each species at each farm were calculated as: Seed Cleaning Cost $=$ total hours to clean seed of each species x labor rate per hour (Supp. Table S4).

Seed lab testing costs. Though not required by Federal Seed Act Regulations for wildflowers, we included the cost of testing seed for germination and viability ( $\$ 56$ per species per year) and purity ( $\$ 39$ per species per year) by the Montana State Seed Laboratory as it is good practice for ensuring quality seed for sale (Supp. Table S4). Germination testing measures seedling emergence and development. Seeds that do not germinate may be dormant and are then tested for viability using a Tetrazoliun (TZ) test (AOSA 2017). Purity measures the percent of a wildflower seed lot that is the species of interest versus weed seeds, other seeds, or inert debris. Due to the expense involved with seed testing, we only requested TZ tests for our seed lots to determine seed viability. We used results of the TZ tests as an overall indicator of total seed lot viability. For our analyses, we considered our harvested seed samples to be $100 \%$ wildflower seeds (i.e., only wildflower seed) because we harvested seed in small batches by hand, resulting 
in very clean seed samples lacking debris and non-wildflower seed, though such purity was not measured explicitly.

Seed packing costs: retail only. In order to estimate the number of packets that could be filled for each of the wildflower species, we determined the amount of seed contained in retail packets and then converted this to seed weight per packet using information on seed count per unit weight contained in the Association of Official Seed Analysts (AOSA) rule book (i.e., set of standard procedures in the United States and Canada for testing seeds) (Supp. Table S6). Penstemon confertus and $P$. hastata are not sold commercially, so we estimated seed numbers per packet for these species based on similar plant species (i.e., other species in the same genus with seeds of similar size, including Penstemon hirsutus (L.) Willd. and Phacelia campanularia A. Gray). When information on weight was not available for the species of interest in the AOSA rule book, we used the closest species available within the genus with similarly sized seeds. If there were no similar species for comparison, we used reported numbers of seeds per unit weight from various online seed companies that also sell seed in larger quantities (Prairie Moon Nursery, Native Ideals Seed Farm, Planet Natural, High Country Gardens, and Great Basin Seed). It should be noted, however, that seed weight may vary considerably within and between species depending on production practices, environmental effects, and harvest timing. We then used the results of our $\mathrm{TZ}$ tests (\% seed viability) to adjust the weight of seed per packet until we reached a minimum of $90 \%$ seed viability for each flower species (Supp. Table S7) to ensure quality seed for sale as: Adjusted Seed Packet Weight $=($ weight of seed per retail packet x 90\% seed viability) / (actual \% seed viability per flower species) (Supp. Table S7). We estimated the total number of seed packets we could fill by hand based on the total weight of seed collected from each wildflower species as: Total Number Seed Packets = total weight of seed per flower 
species / adjusted weight per seed packet (Supp. Tables S7 and S8). We estimated the total cost required to package all seeds of each species for each farm as: Seed Packaging Cost $=$ (total number of seed packets filled per wildflower species / number of seed packets filled per hour) $\mathrm{x}$ (labor rate per hour) (Supp. Table S4, S6 and S8).

Seed envelope costs: retail only. For our analyses we chose plain coin envelopes (5.72 x 8.89 $\mathrm{cm}$ ), which cost $\$ 0.06$ each and are what a small producer might use when selling at farmer's markets. More elaborate packaging strategies involving custom-printed packaging would thus have to take this into account. We did not consider the cost of labeling the envelopes since there are numerous options that will depend on the producer. For 2014 and 2015, we multiplied the total number of seed packets needed per flower species (Supp. Table S8) by $\$ 0.06$ per envelope to estimate, for each farm, the cost of envelopes to package seed of each flower species (Supp. Table S4).

Seed licensing costs. Though not required in the state of Montana for selling wildflower seed, we included the cost of a seed license because other states may require this. The cost is \$225 per farm per year and includes a Dealer license (\$75), Labeler license (\$75), and Seed Grower license (\$75) (Supp. Table S4). We distributed this cost evenly among the nine wildflower species ( $\$ 25$ per species) for analyses.

\section{Income from seed sales (2014-2015)}

Retail seed-sales. For each flower species, we determined the local and regional retail pricing for seed packets (\$1.95-3.99 per packet; Supp. Table S6). For $P$. confertus and $P$. hastata, which are not sold commercially, we estimated the value based on similar species (i.e., other species in the same genus with similarly sized seeds or species with a similar level of seed 
harvesting difficulty; $P$. hirsutus and Penstemon eriantherus Pursh var. argillosus M.E. Jones; Pers. Comm. J. Scianna, USDA Natural Resources Conservation Service, Bridger Plant Materials Center, Bridger, MT). When multiple prices were found for a species, we used the lowest price as a conservative estimate. For 2014 and 2015, we multiplied the total number of seed packets per wildflower species (Supp. Table S8) by the current market value per packet to determine the potential income from seed sales of each flower species and the entire flower strip for each farm (Supp. Table S9).

Wholesale seed-sales. For each flower species, we determined the wholesale value for bulk seeds using a local seed company (Bruce Seed Farm Inc., Townsend, MT). Values ranged from \$28-150 per PLS pound (PLS, or pure live seed, is the percentage of seed that will germinate within a given quantity and is calculated as: $\%$ PLS $=(\%$ seed purity $x \%$ seed viability) / 100 (Supp. Table S6). No bulk pricing was available for three of the species (i.e., $C$. rotundifolia, $P$. confertus and $P$. hastata). Therefore, we based pricing on the level of seed harvesting difficulty, size of seeds, and lack of commercial availability. We used the higher value of $\$ 150$ per PLS pound as an estimate of value; the lack of seed availability may warrant even higher market values (Pers. Comm. G. Pearse, Bruce Seed Farm Inc., Townsend, MT). For 2014 and 2015, we determined the value of bulk seed for each species per farm using the following equation: Bulk Seed Value $=(($ total weight of seed collected for each species per farm $\mathrm{x} \%$ PLS $) / 100)) \mathrm{x}$ (market value of bulk seed) (Supp. Tables S6-S8). 


\section{Cost-benefit analysis (2013-2015)}

Retail seed-sales. For each year and farm, we summed all costs associated with 1) establishing and maintaining the flower strips using Scenario 2 (i.e., higher plug cost) for purchasing plant materials as a conservative estimate of profit and 2) taking a retail seed-sales approach for each wildflower species (Supp. Tables S4 and S9). For each year and farm, we also summed all potential income from retail seed sales for each species (Supp. Table S9). We calculated the overall potential net profit as: Net Profit $=$ income from seed sales - cost to establish and maintain strips - cost to process seeds for sale.

Wholesale seed-sales. We used the same equation above for the wholesale seed sales costbenefit analysis, except that we used Scenario 1 (i.e., lower plug cost) for purchasing plant materials as a conservative estimate of losses (Supp. Tables S4 and S9).

\section{Results}

Costs of establishing and maintaining wildflower strips (2013-2015).

Overall costs associated with establishing and maintaining wildflower strips varied among farms, flower species, and years (Figs. 1 and 2, Supp. Tables S3 and S4). The largest expense associated with establishing and maintaining wildflower strips for all farms was the cost to purchase plant materials for the entire flower strip and depended on whether plugs were to be purchased from a wholesale (Scenario 1) or retail (Scenario 2) nursery (Supp. Table S4). Cost estimates also varied among flower species. We also saw differences among farms in costs to plant wildflower strips, due to differences among farms in planting bed preparation (Tables S1, S3, and S4). Because we planted each flower species at different densities to maximize the use of space and floral display for pollinators, there were also differences in estimated mean costs 
among species resulting from the increased labor to plant and water the species requiring more plugs to be planted due to smaller growth habits (i.e., plant height and spread) (Supp. Table S10). Weeding costs varied among farms for the entire flower strip in all three years (Supp. Tables S3 and S4). Estimated mean costs associated with weeding in 2013 were the same among flower species because of similarities in the amount of bare ground compared to the initial size of the plugs. In subsequent years, as plants grew larger, estimated mean costs associated with weeding varied among flower species (Supp. Table S10). Another large expense was the yearly opportunity cost associated with displacing other salable crops to provide space for the wildflower strips, which was the same among flower species and farms (Supp. Table S4).

\section{Costs of harvesting, cleaning, testing, and packaging seed (2014-2015).}

Overall costs associated with collecting seeds and preparing them for sale varied among farms, wildflower species, and years (Figs. 1 and 2, Supp. Tables S3, S4, and S10). The largest expense associated with taking a seed-sales approach was seed testing and licensing, which was the same for each farm and flower species (Supp. Tables S4 and S10). Estimated mean costs of seed harvesting were among the lowest expense incurred and varied by flower species in 2014 and in 2015 (Supp. Tables S3 and S10). Seed harvesting costs also varied among farms for the entire flower strip (Supp. Tables S3 and S4). Estimated mean costs of cleaning seed varied among flower species in 2014 and 2015 (Supp. Table S10). Seed cleaning costs also varied among farms for the entire flower strip (Supp. Tables S3 and S4). Estimated costs of packaging seed and of seed envelopes, incurred by retail seed sales only, varied among flower species and farm in 2014 and 2015 (Supp. Tables S3, S4, and S10). Differences among flower species in 
seed viability affected the total amount of salable seed and also affected seed packaging and seed envelope costs for the retail seed-sales approach (Supp. Tables S4 and S7).

\section{Income from seed sales (2014-2015).}

We observed large differences among farms and years in the potential income from retail and wholesale seed sales for the entire flower strip (Supp. Table S9). We also saw large differences among wildflower species in potential income from 1) retail seed sales, with $H$. villosa having the highest potential mean income in 2014 and 2015, G. viscosissimum having the lowest income in 2014, and P. hastata the lowest in 2015 (Fig. 1, Supp. Table S11) and 2) wholesale seed sales, with E. speciosus having the highest potential mean income in 2014 and 2015, G. viscosissimum having the lowest income in 2014, and C. rotundifolia the lowest in 2015 (Fig. 2, Supp. Table S11).

\section{Cost-benefit analysis (2013-2015)}

Retail seed-sales: net estimated profit. In the overall retail cost-benefit analysis conducted across all four farms and all three years, we projected that all farms would profit from seed sales, when considering the entire flower strip (Fig. 3, Table 1). However, estimated total profits varied greatly among farms due, for example, to differences in planting and weeding costs resulting from planting bed preparation (i.e., management practices) (Supp. Tables S1, S3, and S4). Across farms, we projected that seven of the nine wildflower species would be profitable from retail seed sales, but estimated profits varied greatly among the flower species (Fig. 3, Table 1). We conducted subsequent robustness analyses to validate the weeding and seed 
harvesting effort indices we used for calculating weeding and seed harvesting costs for the overall cost-benefit analyses. These analyses showed some differences among plant species, but supported the same overall patterns of profitability across all nine species. Therefore, we retained the weeding and seed harvesting indices for all analyses because they more accurately reflected the difference among plant species.

Wholesale seed-sales: net estimated loss. In the overall wholesale cost-benefit analysis conducted across all four farms and all three years, we projected that all farms would suffer similar losses from seed sales, when considering the entire flower strip (Fig. 3, Table 1). Estimated losses were also similar among the flower species (Fig. 3, Table 1).

\section{Discussion}

One of the primary motivations for adopting wildflower strips on farmlands is to increase crop yields. Such benefits should accrue via enhanced pollination services provided when wild bees are more abundant and diverse in the presence of supplemental floral resources. However, other potential benefits remain poorly understood. To our knowledge, among the ecological and economic benefits of pollinator habitat plantings considered to date (reviewed in Uyttenbroeck et al. 2016, Venturini et al. 2017a), the role of flower strips in native wildflower seed production has not been explored (but see Todd et al. 2016 on using sunflower crops as pollinator resources). Our economic analyses indicate that revenue from the retail sale, but not bulk wholesale, of wildflower seed collected from flower strips on four small, diversified farms could exceed the costs associated with establishing and maintaining flower strips after the second growing season. Such an approach may provide an economic incentive to encourage greater adoption of this pollinator conservation strategy. 
The same small farms where we conducted the research reported here harbor $>202$ wild bee species (Delphia et al. 2019), most of which visited the wildflower strips for food resources (Burkle, Delphia, O'Neill, unpublished data). Thus our flower strips helped support high bee diversity. In addition to the ecological benefits, our economic analysis indicates that selling seeds from wildflower strips via retail sale, but not wholesale, has potential to provide an economic advantage. The differences in profitability we observed depended on factors associated with the farm (i.e., weed pressure, planting bed preparation) that affected planting and weeding costs as well as wildflower growth, flowering, and ultimately seed production. Other factors affecting profitability included differences between wildflower species in costs associated with weeding and with processing and cleaning seeds. Our findings indicate that some wildflower species may be more profitable to grow for seed sales than others and the discrepancy in profitability can further be affected by local climate and farm management practices. Income could potentially be even higher if farmers took a targeted approach of collecting seeds only from those species with the greatest profitability each year, yet still providing a diverse suite of plants for pollinators by growing all species.

Retail seed sales require added labor for filling individual seed packets, which may provide a disincentive to some farmers. Thus, we explored bulk seed sales as a potentially more attractive and less time-intensive option. However, our wildflower strips were not large enough to make a wholesale seed-sales approach viable after accounting for 1) the low amount of seed harvested per species at each farm (i.e., flower strips only produced a pound of seed at two farms for three plant species in 2014 and at one farm for one species in 2015), 2) the low percentage pure live seed (PLS) often typical of wildflower seed, which substantially lowers the amount of salable seed (e.g., PLS for seed from our flower species ranged from 16.5\% to $99 \%$, depending on the 
farm, species, and year), and 3) the much lower price per unit weight compared to retail seed sales. For example, a farmer would need to produce anywhere from c. 1.5 to $11 \mathrm{lbs}$ of seed per species with $100 \%$ PLS just to break even in the second year. Alternatively, a farmer could take a targeted approach and focus on growing those species with the highest bulk value, but this could reduce the overall floral (and perhaps bee) diversity within the strips if limited space is a concern. Larger-scale plantings would also likely require alternative weeding methods and mechanized seed harvesting to lower labor costs associated with hand-weeding flower strips and hand-harvesting seed. Opportunity costs of displacing salable crops would also be increased with larger flower plantings unless flower plantings were placed on field margins or other noncrop lands. Several of the species that we grew in our flower strips are not currently available for wholesale, despite known conservation value to bees (e.g., P. hastata; Ogle et al. 2011, 2012), likely because the methods to mechanically harvest seed on a large scale have not yet been fully resolved (LeFebvre et al. 2017). For other species, it may be that the market (or demand) does not yet exist to make wholesale seed production a viable option. Therefore, assigning value to these species may overestimate the reported profitability and is a limitation of our study.

Our research suggests that farmers planting flower strips could help fill the increasing need for locally produced, regionally appropriate, native wildflower seed for use in a multitude of applications, including other pollinator and wildlife habitat conservation projects and post-fire restoration (e.g., Tuell et al. 2008, Isaacs et al. 2009, Peppin et al. 2010, USDA-FS 2012, The White House 2015a, b). One seed mix or suite of native plants will not be sufficient to use across all regions since flower species may vary in their attractiveness or ability to support the local bee fauna (e.g., Williams et al. 2015). Therefore, this native seed production strategy could be 
replicated regionally to produce seed from different suites of plant species suitable to each habitat and tailored to the local pollinators.

To implement this strategy, seeds could be marketed with an indication that they originated from farms actively engaged in pollinator conservation. Such marketing strategies have been successfully employed for food products grown on farms that have adopted a conservationminded farming protocol (e.g., 'Fair to Nature' in the U.K. (http://www.conservationgrade.org) and Bee Better Certified ${ }^{\mathrm{TM}}$ in the U.S. (http://beebettercertified.org). Some farmers might also be interested in not only the increased income, but enhanced social capital for their role in supporting this practice. Farmers desiring to establish pollinator habitat, but without interest or time to be directly involved in harvesting and selling wildflower seed, could develop partnerships with seed producers, retailers, or plant nurseries that harvest the seed in exchange for yearly maintenance associated with wildflower plantings.

Only a few studies have documented the costs required to plant and maintain wildflower strips (e.g., Blaauw and Isaacs 2014, Venturini et al. 2017b). In our study, most of the costs associated with flower strips were incurred in the first year with a subsequent yearly baseline investment in weeding. Providing information on the costs of this pollinator-conservation strategy allows farmers to make informed decisions on whether they can afford to implement this approach when economic return is either delayed or unrealized. For example, crop yields attributed to increased pollination may be crop- or region-specific (Sardinias and Kremen 2015) and require a number of years to offset the costs of flower plantings (e.g., Blaauw and Isaacs 2014, Venturini et al. 2017b), thereby making it difficult to predict potential profits. The approach that we have outlined for increasing revenue may allow for more predictability (though 
bulk wildflower seed pricing can be highly volatile between years) and a quicker return rate on the initial investment. For some farmers, however, supporting wild bees and increased farmland biodiversity may be reason enough to provide pollinator habitat.

Another yearly expense of implementing wildflower strips was the opportunity cost associated with loss of ground that could be used for other salable crops. This cost will vary with the farming system/type, the crops being displaced, market values, and the geographic region. For our purposes, we used a net revenue value targeted at small-scale, diversified farms with retail and direct-to-consumer sales. Therefore, we potentially overestimated net revenue when calculating opportunity costs. However, we consider our analysis to be a useful illustration of some of the costs and benefits of planting wildflower strips rather than an economic analysis that applies to all situations. One strategy to reduce opportunity cost would be to place wildflower strips on areas of farms that are less ideal or unsuitable for crop production. Indeed, the type of land selected by landowners for enrollment into pollinator habitat conservation is that with low crop production value (Jones Ritten et al. 2017).

Understanding the full range of costs and benefits of pollinator habitat plantings enables farmers to make informed decisions regarding adoption of such strategies (Uyttenbroeck et al. 2016, Venturini et al. 2017a). In addition to providing forage for wild bees, enhancing pollination services in some cropping systems, and now providing native seed for potential sales, non-crop flower plantings can serve many other important roles, such as enhancing soil nitrogen when flowering leguminous cover crops are used in crop rotations (Ellis and Babercheck 2015), supporting natural enemies for pest suppression (Blaauw and Isaacs 2015), reducing soil erosion (Wratten et al. 2012, Ellis and Barbercheck 2015), and providing windbreaks that reduce wind speed and benefit crop yields (Vaughan and Black 2006). More research is needed to understand 
some of the other environmental and economic benefits of wildflower strips within the numerous agroecosystems across North America and the globe.

Our cost-benefit analyses for both retail and wholesale seed sales included three years of empirical data based on our farm partners and small-scale flower strip plantings $(<1 \%$ of the cropped area) and our local resources (nurseries and seed companies). We note that profits from retail seed sales would have been higher if we used the lower plug costs to calculate net profits. Similarly losses from wholesale seed sales would have been greater if we used the higher plug costs to calculate net losses. It should also be noted that our estimated profits from retail sales assumes a best-case scenario where a market is available for all seeds produced. Often famers growing vegetable seed for sale to larger commercial companies are contracted to grow particular species projected to be in demand. Thus, each farmer would have to assess the available market and determine costs associated with the inability to sell all seeds harvested or develop partnerships with potential seed buyers beforehand. However, a farmer would not need to sell all seed to at least break even. In addition, wildflowers would presumably continue to produce seed beyond the study period as they are perennials, therefore potentially providing a continued source of revenue. Further research will be needed to fully evaluate and optimize this seed-sales approach for pollinator conservation in other farming systems and regions of the country, but our findings provide a first step and suggest much potential.

\section{Author's Contributions}

CMD, LAB, and KMO conceived the ideas, designed methodology, and conducted to the costbenefit analysis. CMD coordinated field work with assistance of LAB and KMO. CMD 
wrote the first draft of the manuscript and all authors contributed critically to subsequent drafts and gave final approval for publication.

\section{Acknowledgements}

This project was supported by a Western Sustainable Agriculture Research and Education grant (SW13-043) awarded to LAB, CMD, and KMO. We thank Laura Smith and Robert Dunn (Westscape Wholesale Nursery) for providing helpful comments on the manuscript. We thank participating farmers Matt and Jacy Rothschiller, Pete and Nancy Fay, John and Conni Mahoney, Charles Holt, and Macdonald Burgess; field and laboratory assistants Jess Monte, Cecilia Welch, Alisha Gill, and Melissa Bakosh; Justin Runyon for technical support; the MT State Seed Lab for use of equipment and helpful advice; and Joseph Scianna (Bridger Plant Materials Center) and Gordon Pearse (Bruce Seed Farm Inc.) for advice on wholesale and retail seed pricing. The authors have no conflicts of interest to report. 


\section{References Cited}

Aldrich, J.H. 2002. Factors and benefits in the establishment of modest-sized wildflower plantings: a review. Native Plants Journal. 3: 67-86.

Allen-Wardell, G., P. Bernhardt, R. Bitner, A. Burquez, S. Buchmann, J. Cane, P. A. Cox, V. Dalton, P. Feinsinger, M. Ingram, and D. Inouye. 1998. The potential consequences of pollinator declines on the conservation of biodiversity and stability of food crop yields. Conserv. Biol. 12: $8-17$.

AOSA. 2017. AOSA rules for testing seeds. Association of Official Seed Analysts, Wichita, KS.

Batáry, P., L. V. Dicks, D. Kleijn, and W. J. Sutherland. 2015. The role of agri-environment schemes in conservation and environmental management. Conserv. Biol. 29: 1006-1016.

Biesmeijer, J. C., S. P. Roberts, M. Reemer, R. Ohlemüller, M. Edwards, T. Peeters, A. P. Schaffers, S. G. Potts, R. Kleukers, C. D. Thomas, J. Settele. 2006. Parallel declines in pollinators and insect-pollinated plants in Britain and the Netherlands. Science. 313: 351-354.

Blaauw, B. R., and R. Isaacs. 2014. Flower plantings increase wild bee abundance and the pollination services provided to a pollination-dependent crop. J. Appl. Ecol. 51: 890-898. 
Blaauw, B. R. and R. Isaacs. 2015. Wildflower plantings enhance the abundance of natural enemies and their services in adjacent blueberry fields. Biol. Control. 91: 94-103.

Bujak, C.M. 2015. Seed dormancy and greenhouse propagation of arrowleaf balsamroot (Balsamorhiza sagittata) and silverleaf phacelia (Phacelia hastata var. hastata). M.S. thesis, Montana State University, Bozeman.

Burkle, L. A., C. M. Delphia, K. M. O’Neill. 2017. A dual role for farmlands: food security and pollinator conservation. J. Ecol. 105: 890-899.

Cane, J. H. 2005. Pollination potential of the bee Osmia aglaia for cultivated red raspberries and blackberries (Rubus: Rosaceae). Hortscience. 40: 1705-1708.

Delphia, C.M., T. Griswold, E. G. Reese, K. M. O'Neill, and L. A. Burkle. 2019. Checklist of bees (Hymenoptera: Apoidea) from small diversified vegetable farms in south-western Montana. Biodivers. Data J. 7: e30062.

Ellis, K. E., and M. E. Barbercheck. 2015. Management of overwintering cover crops influences floral resources and visitation by native bees. Environ. Entomol. 44: 999-1010.

Ellis, J. D., J. D. Evans, and J. Pettis. 2010. Colony losses, managed colony population decline, and Colony Collapse Disorder in the United States. J. Apicult. Res. 49: 134-136. 
Erickson, V. 2008. Developing native plants germplasm for national forests and grasslands in the Pacific Northwest. Native Plants Journal. 9: 255-266.

Gallai, N., J. M. Salles, J. Settele, and B. E. Vaissière. 2009. Economic valuation of the vulnerability of world agriculture confronted with pollinator decline. Ecol. Econ. 68: $810-821$

Garibaldi, L. A., I. Steffan-Dewenter, R. Winfree, M. A. Aizen, R. Bommarco, S. A. Cunningham, C. Kremen, L. G. Carvalheiro, L. D. Harder, O. Afik, and I. Bartomeus. 2013. Wild pollinators enhance fruit set of crops regardless of honey bee abundance. Science. 339: 1608-1611.

Geldmann, J., and J. P. González-Varo. 2018. Conserving honey bees does not help wildlife. Science. 359: 392-393.

Greenleaf, S. S., and C. Kremen. 2006. Wild bees enhance honey bees' pollination of hybrid sunflower. P. Natl. Acad. Sci. 103: 13890-13895.

Goulson, D., E. Nicholls, C. Botías, and E. L. Rotheray. 2015. Bee declines driven by combined stress from parasites, pesticides, and lack of flowers. Science. 347: 1255957.

Haaland, C., R. E. Naisbit, and L. F. Bersier. 2011. Sown wildflower strips for insect conservation: a review. Insect Conserv. Diver. 4: 60-80. 
Hurd, P. D., E. G. Linsley, and T. W. Whitaker. 1971. Squash and gourd bees (Peponapis, Xenoglossa) and the origin of the cultivated Cucurbita. Evolution. 25: 218-234.

Isaacs, R., J. Tuell, A. Fiedler, M. Gardiner, and D. Landis. 2009. Maximizing arthropodmediated ecosystem services in agricultural landscapes: the role of native plants. Front. Ecol.

Environ. 7: 196-203.

Javorek, S. K., K. E. Mackenzie, and S. P. Vander Kloet. 2002. Comparative pollination effectiveness among bees (Hymenoptera: Apoidea) on lowbush blueberry (Ericaceae: Vaccinium angustifolium). Ann. Entomol. Soc. Am. 95: 345-351.

Jones Ritten, C., C. Bastian, J. Shogren, T. Panchalingam, M. Ehmke, and G. Parkhurst. 2017. Understanding pollinator habitat conservation under current policy using economic experiments. Land. 6: 57.

Kennedy, C. M., E. Lonsdorf, M. C. Neel, N. M. Williams, T. H. Ricketts, R. Winfree, R. Bommarco, C. Brittain, A. L. Burley, D. Cariveau, and L. G. Carvalheiro. 2013. A global quantitative synthesis of local and landscape effects on wild bee pollinators in agroecosystems. Ecol. Lett. 16: 584-599. 
Klein, A. M., B. E. Vaissiere, J. H. Cane, I. Steffan-Dewenter, S. A. Cunningham, C. Kremen, and T. Tscharntke. 2007. Importance of pollinators in changing landscapes for world crops. P. R. Soc. B. 274: 303-313.

LeFebvre, J., J. Scianna, and M. Pokorny. 2017. Plant Guide for silverleaf phacelia (Phacelia hastata). USDA-Natural Resources Conservation Service, Bridger Plant Materials Center, Bridger, MT.

Losey, J. E., and M. Vaughan. 2006. The economic value of ecological services provided by insects. Bioscience. 5: 311-323.

Lundin, O., K. L. Ward, and N. M. Williams. 2019. Identifying native plants for coordinated habitat management of arthropod pollinators, herbivores and natural enemies. J. Appl. Ecol. 56: 665-676.

Michener, C. D. 2007. The bees of the world. The Johns Hopkins University Press, Baltimore, MD.

Morandin, L. A., R. F. Long, and C. Kremen. 2016. Pest control and pollination cost-benefit analysis of hedgerow restoration in a simplified agricultural landscape. J. Econ. Entomol. 109: 1020-1027. 
Norcini, J. G. 2006. Native plants: an overview. Environmental Horticulture Department, Florida Cooperative Extension Service, Institute of Food and Agricultural Sciences, University of Florida. Document ENH1045, Gainesville, FL.

Odeh, O., and J. Hairston. 2014. Making a dollar per square foot: dream or reality? J. of Extension [On-line]. 52(5) Article 5COM2. Available at: https://joe.org/joe/2014october/comm2.php

Ogle, D., L. St. John, M. Stannard, and L. Holzworth. 2012. Plant Materials Technical Note ID24: Conservation plant species for the Intermountain West. USDA-NRCS, Boise, ID.

Ogle, D., D. Tilley, J. Cane, L. St. John, K. Fuller, M. Stannard, and P. Pavek. 2011. Plant Materials Technical Note No. 2A: Plants for pollinators in the Intermountain West. USDANRCS, Boise, ID.

Pascual, U., and C. Perrings. 2007. Developing incentives and economic mechanisms for in situ biodiversity conservation in agricultural landscapes. Agr. Ecosyst. Environ. 121: 256-268.

Peppin, D. L., P. Z. Fulé, J. C. Lynn, A. L. Mottek-Lucas, and C. Hull Sieg. 2010. Market perceptions and opportunities for native plant production on the southern Colorado plateau. Restor. Ecol. 18: 113-124. 
Potts, L. E., M. J. Roll, and S. J. Wallner. 2002. Colorado native plant survey-Voices of the green industry. Native Plants Journal. 3: 121-125.

Potts, S. G., J. C. Biesmeijer, C. Kremen, P. Neumann, O. Schweiger, and W. E. Kunin. 2010. Global pollinator declines: trends, impacts and drivers. Trends Ecol. Evol. 25: 345-353.

Pywell, R. F., M. S. Heard, B. A. Woodcock, S. Hinsley, L. Ridding, M. Nowakowski, and J. M. Bullock. 2015. Wildlife-friendly farming increases crop yield: evidence for ecological intensification. P. R. Soc. B. 282: 20151740.

Richards, R. T., J. C. Chambers, and C. Ross. 1998. Use of native plants on federal lands: policy and practice. J. Range Manage. 51: 625-632.

Sardiñas, H. S., and C. Kremen. 2015. Pollination services from field-scale agricultural diversification may be context-dependent. Agr. Ecosyst. Environ. 207: 17-25.

Scheper, J., A. Holzschuh, M. Kuussaari, S. G. Potts, M. Rundlöf, H. G. Smith, and D. Kleijn. 2013. Environmental factors driving the effectiveness of European agri-environmental measures in mitigating pollinator loss-a meta-analysis. Ecol. Lett. 16: 912-920.

Scheper, J., R. Bommarco, A. Holzschuh, S. G. Potts, V. Riedinger, S. P. Roberts, M. Rundlöf, 
H. G. Smith, I. Steffan-Dewenter, J. B. Wickens, and V. J. Wickens. 2015. Local and landscapelevel floral resources explain effects of wildflower strips on wild bees across four European countries. J. Appl. Ecol. 52: 1165-1175.

Todd, K. J., M. M. Gardiner, and E. D. Lindquist. 2016. Mass flowering crops as a conservation resource for wild pollinators (Hymenoptera: Apoidea). J. Kansas Entomol. Soc. 89: 158-167.

Tuell, J. K., A. K. Fiedler, D. Landis, and R. Isaacs. 2008. Visitation by wild and managed bees (Hymenoptera:Apoidea) to eastern U.S. native plants for use in conservation programs. Environ. Entomol. 37: 707-718.

USDA FS. 2012. Native plant materials policy: a strategic framework. U.S. Forest Service-1006, Washington, DC.

Uyttenbroeck, R., S. Hatt, A. Paul, F. Boeraeve, J. Piqueray, F. Francis, S. Danthine, M. Frederich, M. Dufrêne, B. Bodson, and A. Monty. 2016. Pros and cons of flowers strips for farmers. A review. Biotechnol. Agron. Soc. 20: 225-235.

Vanslembrouck, I., G. Huylenbroeck, and W. Verbeke. 2002. Determinants of the willingness of Belgian farmers to participate in agri-environmental measures. J. Agri. Econ. 53: 489-511.

Vaughan, M., and S. H. Black. 2006. AF Note-32: Sustaining native bee habitat for crop pollination. Portland, OR: USDA. 
Vaughan, M., and M. Skinner. 2008. Using Farm Bill programs for pollinator conservation. USDA NRCS National Plant Data Center, http://www. xerces.org/wpcontent/uploads/2008/11/using_farm_bill_programs_xerces_society.pdf.

Venturini, E. M., F. A. Drummond, A. K. Hoshide, A. C. Dibble, and L. B. Stack. 2017 a. Pollination reservoirs for wild bee habitat enhancement in cropping systems: A review. Agroecol. Sust. Food. 41: 101-142.

Venturini, E.M., F. A. Drummond, A. K. Hoshide, A. C. Dibble, and L. B. Stack. (2017b) Pollination reservoirs in lowbush blueberry (Ericales: Ericaceae). J. Econ. Entomol. 110: 333346.

White House. 2015a. National strategy to promote the health of honey bees and other pollinators. Washington, DC: Pollinator Health Task Force.

White House. 2015b. Pollinator-friendly best management practices for federal lands. Washington, DC: Pollinator Health Task Force.

Williams, N. M., K. L. Ward, N. Pope, R. Isaacs, J. Wilson, E. A. May, J. Ellis, J. Daniels, A. Pence, K. Ullmann, and J. Peters. 2015. Native wildflower plantings support wild bee abundance and diversity in agricultural landscapes across the United States. Ecol. Appl. 25: 2119-2131.

Winfree, R., N. D. Williams, J. Dushoff, and C. Kremen. 2007. Native bees provide insurance against ongoing honey bee losses. Ecol. Lett. 10: 1105-1113. 
Winfree, R., I. Bartomeus, and D. P. Cariveau. 2011. Native pollinators in anthropogenic habitats. Annu. Rev. Ecol. Evol. S. 42: 1-22.

Wratten, S. D., M. Gillespie, A. Decourtye, E. Mader, and N. Desneux. 2012. Pollinator habitat enhancement: benefits to other ecosystem services. Agr. Ecosyst. Environ. 159: 112-122. 
Figure 1. Mean ( \pm SE) yearly $(A)$ cost to establish and maintain flower strips (Cost 1$),(B)$ cost to undertake a retail seed-sales approach (Cost 2), (C) total cost $($ Cost $1+2)$, (D) estimated potential income from retail seed sales, and (E) estimated net profit for each wildflower species among four farms. All values in USD. 

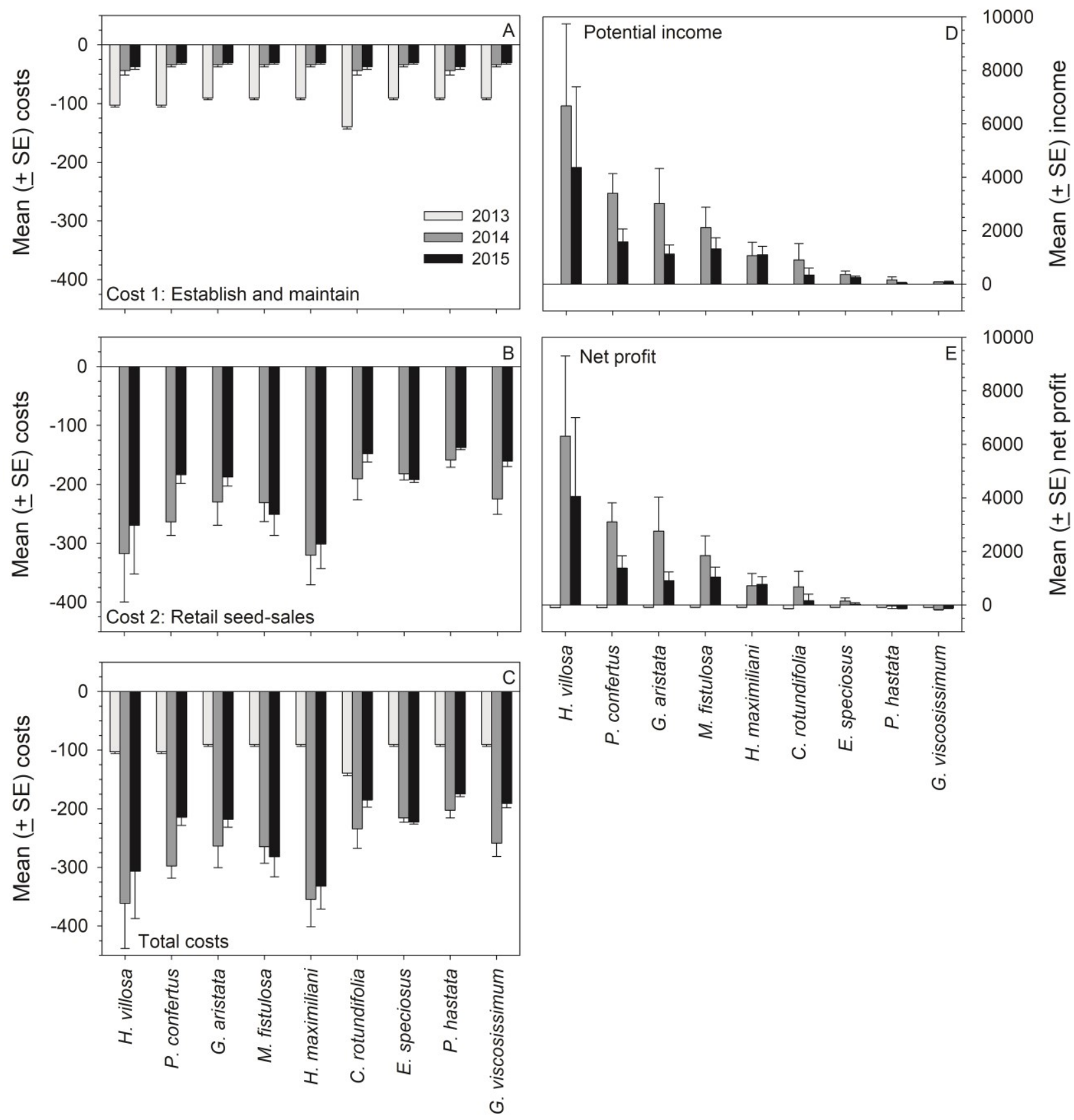

Figure 2. Mean ( \pm SE) yearly (A) cost to establish and maintain flower strips (Cost 1$)$, (B) cost to undertake a wholesale seed-sales approach (Cost 2), (C) total cost (Cost $1+2)$, (D) estimated potential income from bulk wholesale seed sales, and (E) estimated net loss for each wildflower species among four farms. All values in USD. 

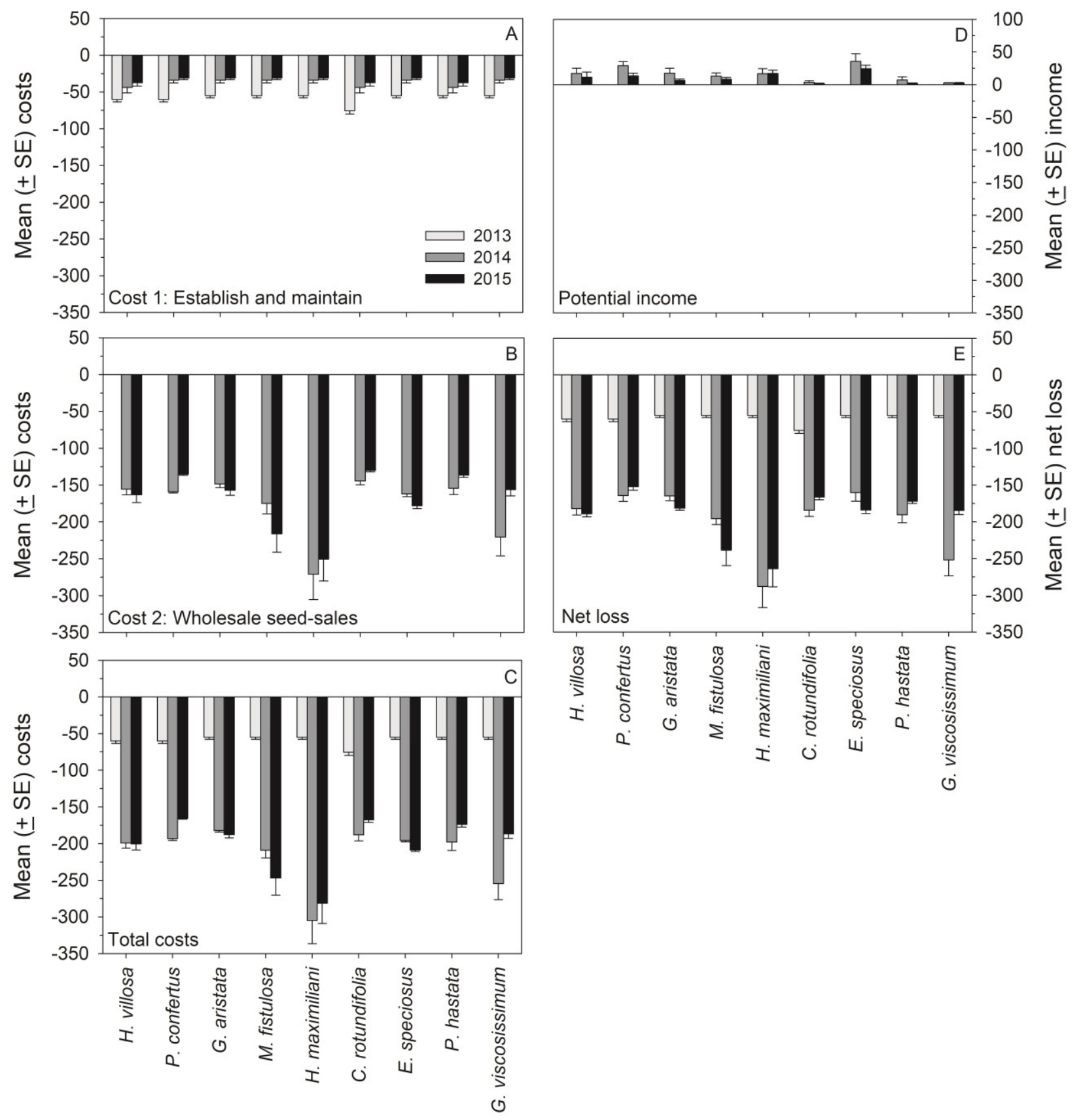

Figure 3. Mean $( \pm \mathrm{SE})$ estimated net profits (USD) from retail and wholesale seed sales costbenefit analysis (2013-2015) for each wildflower species among four farms. 


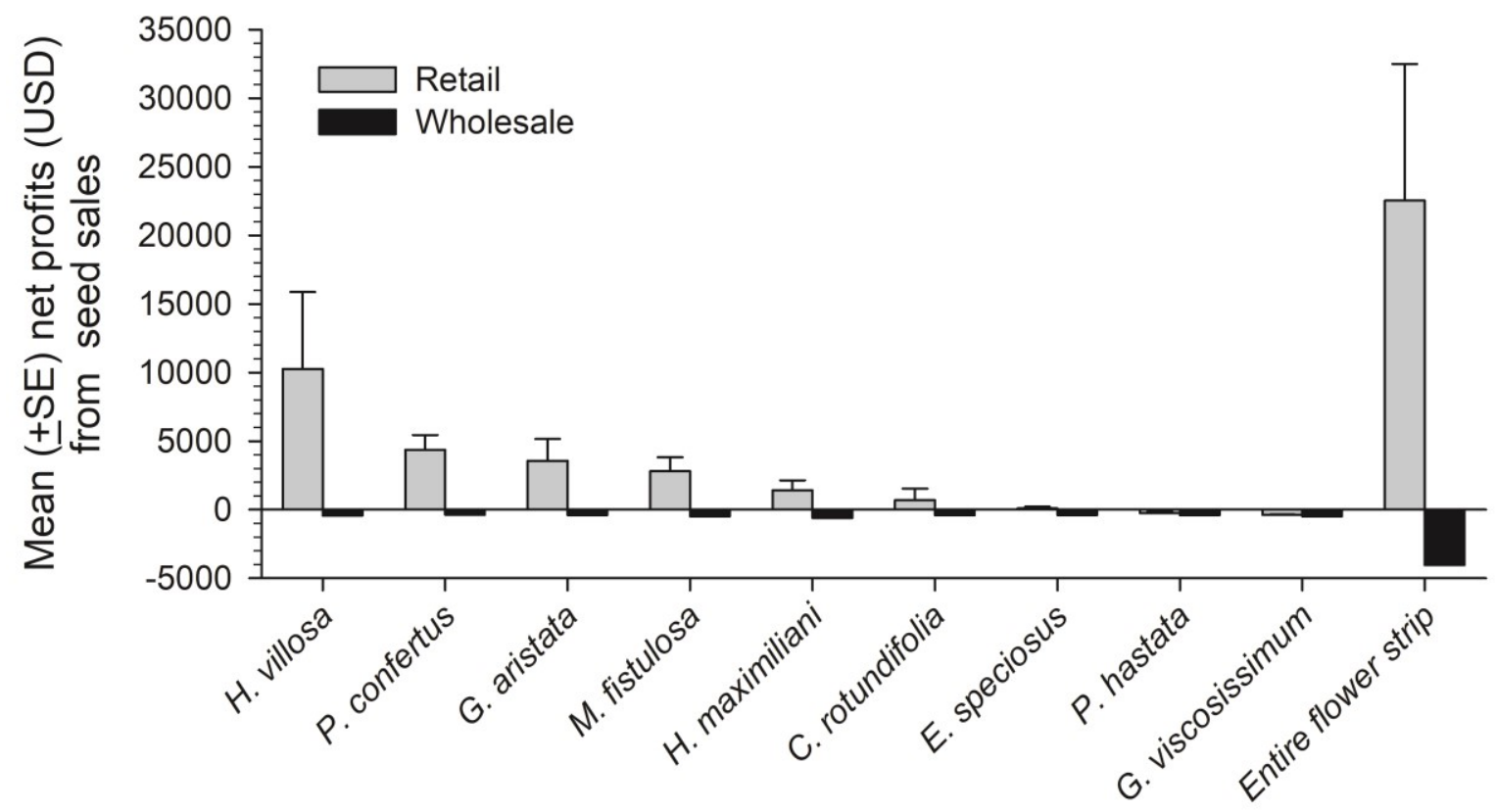


824 Table 1. Total estimated net profits (USD) from retail seed sales and net losses from wholesale 825 seed sales cost-benefit analysis (2013-2015) for each wildflower species on each of four farms.

Farm

\begin{tabular}{lrrrr} 
Scientific name & \multicolumn{1}{c}{$\mathbf{1}$} & $\mathbf{2}$ & \multicolumn{1}{c}{$\mathbf{3}$} & \multicolumn{1}{c}{$\mathbf{4}$} \\
\hline & \multicolumn{4}{c}{ Retail Seed-Sales } \\
H. villosa & 8270.66 & 4445.34 & 1724.14 & 26589.03 \\
P. confertus & 3568.78 & 3223.43 & 3164.88 & 7533.49 \\
G. aristata & 7193.19 & 671.05 & 1156.69 & 5263.52 \\
M. fistulosa & 4721.15 & 2638.90 & 22.62 & 3816.22 \\
H. maximiliani & 1258.17 & 721.41 & 99.59 & 3498.32 \\
C. rotundifolia & -77.97 & 153.56 & -447.40 & 3146.47 \\
E. speciosus & 389.85 & 9.05 & -160.59 & 112.18 \\
P. hastata & -331.30 & -419.82 & -375.22 & 71.92 \\
G. viscosissimum & -413.45 & -364.94 & -411.82 & -330.64 \\
Total (2 years income) & $\mathbf{2 4 5 7 9 . 0 7}$ & $\mathbf{1 1 0 7 7 . 9 8}$ & $\mathbf{4 7 7 2 . 8 9}$ & $\mathbf{4 9 7 0 0 . 5 1}$
\end{tabular}

H. villosa

P. confertus

G. aristata

M. fistulosa

H. maximiliani

C. rotundifolia

E. speciosus

P. hastata

G. viscosissimum

Total (2 years income)
Wholesale Seed-Sales

\begin{tabular}{llll}
\hline-410.48 & -420.20 & -476.65 & -417.83 \\
-376.63 & -386.30 & -405.95 & -337.56 \\
-378.30 & -410.93 & -413.27 & -402.43 \\
-538.81 & -526.91 & -426.05 & -465.53 \\
-745.88 & -505.40 & -560.64 & -617.52 \\
-395.08 & -432.36 & -465.82 & -412.36 \\
-371.60 & -401.15 & -432.69 & -391.79 \\
-380.12 & -414.79 & -459.46 & -415.24 \\
$\mathbf{- 5 2 7 . 1 5}$ & -459.44 & -440.03 & -538.68 \\
$\mathbf{- 4 1 2 4 . 0 5}$ & $\mathbf{- 3 9 5 7 . 4 8}$ & $\mathbf{- 4 0 8 0 . 5 5}$ & $\mathbf{- 3 9 9 8 . 9 5}$
\end{tabular}

